\title{
A new President, a new Congress and the path to personalized medicine
}

\section{"Although President Obama did not discuss the issue of personalized medicine in his campaign, per se, in fact, he probably never uttered the phrase, there is ample evidence that his commitment is genuine."}

On 20 January 2009, a jubilant crowd of almost 2,000,000 spectators jammed shoulder-toshoulder on the National Mall in Washington [DC, USA] to witness the inauguration of Barack Obama as the 44th President of the USA. As well as the many other historic firsts that day, a milestone was reached that went little noticed except by relatively few health policy aficionados - America had inaugurated its first President for the era of personalized medicine. This distinction rings true, not so much because President Obama's term of office coincides with a time of unprecedented understanding of the human condition at a molecular level - though that is certainly the case - but more because the new President, joined by many congressional leaders and other key policymakers, both understands and endorses the scientific and economic rationales of personalized medicine.

On Capitol Hill (DC, USA), the 111th Congress will be considering a number of personalized medicine-centric proposals in addition to a major undertaking to enact systemic healthcare reform. The regulatory agencies, especially the US FDA and the Centers for Medicare and Medicaid Services (CMS [MD, USA]), will also be making important decisions that will have an impact on both the approval of new therapeutics and diagnostics, as well as reimbursement for their costs. In the research community, new technologies will debut, the costs of genome-wide association studies will continue to decline and genomic discovery will continue at a prolific pace. All of these scenarios will be closely watched by the private sector, the private insurers and investors in a volatile global economy.

\section{8: setting the stage}

Before discussing, in greater detail, what lies ahead in 2009, it is important to look back at the events of 2008 , for in many ways they presaged what will unfold in the year ahead. With the frenetic pace of the Obama administration, it is difficult to remember that even in the far quieter days of the Bush administration, there was a steadily building drumbeat of support in government for personalized medicine. For the most part, this was a behind-the-scenes effort, with senior officials in agencies determining how best to coordinate their programs and policies. While this may not have been a glamorous or high profile process, it was nonetheless essential, especially at the Department of Health and Human Services (HHS [DC, USA]) which houses the bulk of the agencies critical to personalized medicine, from the better known FDA, CMS and the NIH, to the less well known, but increasingly important, Agency for Healthcare Research and Quality (AHRQ [MD, USA]).

Former HHS Secretary, Mike Leavitt, and his team deserve much credit for this coordinative process and for giving personalized medicine a cabinet-level advocate in the Bush administration. The secretary came to appreciate the power of genetic information during his tenure as Governor of Utah (UT, USA) where he was involved with both the extensive genealogy records of the Mormon Church and the genetic research efforts at the University of Utah. Secretary Leavitt made a commitment to personalized medicine, and he spoke about it with a depth and clarity that went beyond the usual talking points supplied by a staffer. He capped off the year by hosting a summit in Park City (UT, USA) that brought together key leaders in the field and established priorities for advancing personalized medicine over some of the regulatory, scientific and market hurdles.

In the White House, a subcommittee of the President's Council of Advisors on Science and Technology (PCAST [DC, USA]), chaired by Dr Kathleen Behrens (PCAST), released a comprehensive report on personalized medicine.

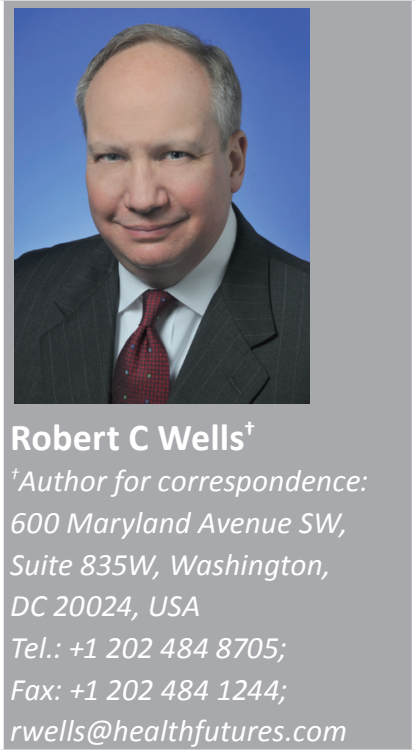

future medicine $^{\text {pot }}$ fsg 
This report provided an overview of issues and a series of recommendations to move the field forward. While the report was well written and thoughtful, from a policy perspective it served an enhanced purpose: for the first time, personalized medicine was elevated to a prominent place on the White House science agenda.

Throughout 2008, Congress was largely silent on many healthcare issues as the Democratic leaders of the House and Senate awaited the November election that they hoped would bring a Democrat to the Oval Office and increase party majorities in both houses. However, Congress did pass one significant piece of legislation to significantly boost the cause for personalized medicine. After a 13-year struggle, the Genetic Information Nondiscrimination Act (GINA) became law in May 2008. Although the majority of the states already had laws that, to one degree or another, outlawed the use of genetic information to discriminate against an individual, GINA created a federal standard covering all 50 states and prohibited discrimination in employment and health insurance. GINA was the product of hard-fought compromise, and like all legislative compromises, it emerged as less than perfect. It did not cover life, long-term care or disability insurance. Nonetheless, GINA remains the most prominent law to date that embodies the goals of personalized medicine by protecting individual privacy.

Finally, two regulatory events took place in 2008 that demonstrated the fault lines that exist, even within the growing community of stakeholders, who share the goal of wanting to move towards more personalized healthcare but can disagree, sometimes passionately, on how best to get there. One event was down to the wire until literally the last hours of the Bush administration, while the other delivered an unexpected shock to the policy community in December 2008. Together, they raised one of the most fundamental questions that confronts personalized medicine, one that neither the Obama administration nor Congress will be able to avoid: how much regulatory oversight of personalized medicine is too much? How much is not enough? Is there a way for policy makers to get it 'just right'?

For more than 2 years the FDA had been trying to promulgate a series of rules regarding in vitro diagnostic assays, known by the pithy title, the 'In Vitro Diagnostic Multivariate Index Assays' (IVD/MIA) guidelines. In doing so, the agency was fighting a two-front skirmish.
It was unclear whether the FDA had the statutory authority to even draft rules in this area, and there were a number of parties who argued strongly that they did not. The second front was the FDA's ongoing efforts to address the concerns of a broad range of parties, especially those in industry who felt that the proposed guidelines would cripple innovation on the part of the small companies that constitute much of the biotech industry.

\section{"...the report ... served an enhanced purpose ... for the first time, personalized medicine was elevated to a prominent place on the White House science agenda."}

In the last days of the Bush administration it looked as though the IVD/MIA guidelines were nearing final approval, having been modified significantly from their original draft. Then, a policy bombshell was dropped in the form of an open letter to the FDA - known as a Citizen's Petition - from Genentech (CA, USA), a company that many consider to be the embodiment of personalized medicine owing to its therapeutics, such as herceptin, which are paired with companion diagnostic tests. Genentech requested that the FDA regulate all laboratory-developed diagnostic tests, a proposition that went well beyond the narrower issues in the proposed IVD/MIA guidelines.

As one might expect, the Genentech petition stirred a hornet's nest of controversy in the personalized medicine community. The arguments mirrored the debate over the IVD/MIA guidelines, though with perhaps even greater intensity. Groups such as the Coalition for 21st Century Medicine (DC, USA) (which represents the interests of diagnostics companies, clinical laboratories, venture capitalists and some patient advocacy groups) criticized Genentech's position, claiming it would delay the introduction of 'critically needed' diagnostic tests and that it ignored regulatory requirements already imposed on laboratories under the Clinical Laboratory Improvement Amendments, which is overseen by CMS. The coalition contended that FDA regulation of all laboratory-developed tests would impose huge costs on laboratories and put significant pressure on the FDA's, already limited, budget and personnel. Conversely, groups such as the Genetics and Public Policy Center (DC, USA) strongly supported the Genentech position with the Center saying in a press release, 
"The future of personalized medicine - and its promises to improve health - depend on safe and effective drugs and validated tests. But if the FDA regulates only drugs used as part of personalized medicine, and not the tests used to prescribe such drugs, it is missing half the equation."

Interestingly, some of the most outspoken critics and supporters of the Genentech petition did agree on one thing: they disliked the proposed IVD/MIA guidelines. Some condsidered them too weak, while others thought they were over-reaching. The swirl of controversy proved to be so potent for the outgoing Bush administration that it was decided to abandon the IVD/MIA guidelines and leave the whole issue of regulatory oversight on the doorstep for the incoming Obama administration and the new Congress.

\section{The personalized medicine President}

Although President Obama did not discuss the issue of personalized medicine in his campaign, per se, in fact, he probably never uttered the phrase, there is ample evidence that his commitment is genuine. In 2006, his second year in the US Senate, then-Senator Obama introduced the Genetics and Personalized Medicine Act, the first legislation specifically crafted to support the cause of personalized medicine. A second version of the bill was introduced in 2007, this time with a Republican cosponsor, Senator Richard Burr of North Carolina, USA. (Representative Patrick Kennedy of Rhode Island later introduced a version of the bill in the US House of Representatives).

Although neither version of the bill passed the Senate, let alone became law, it served a vital role as a reference point, a 'true north' for the public policy discussion over personalized medicine. If one was to begin a conversation on almost any aspect of the subject, you were likely to be asked, 'Is that in the Obama-Burr bill?'

Throughout his presidential campaign, candidate Obama's standard stump speech contained arguments in favor of electronic medical records (a subset of health IT - a major component of personalized healthcare). He also often spoke about the value of prevention and wellness, an often-cited benefit of personalized medicine. To some extent, these were easy issues - after all, both Hillary Clinton and John McCain supported them too - but the Obama position displayed a more sophisticated understanding of the shifting economics of a personalized medicine model. In the final presidential debate, when asked how he would overhaul healthcare, Senator Obama replied,

\section{"And we are going to make sure that we manage chronic illnesses, like diabetes and heart disease, that cost a huge amount but could be prevented. We've got to put more money into preventive care. This will cost some money on the front end, but over the long term, this is the only way that, not only are we going to make families healthy, but it's also how we're going to save the federal budget because we can't afford these escalating costs."}

The President reiterated the point in the White House Forum on Health Reform, 5 March 2009, saying,

"But capturing those savings will take some time. Health IT is going to save money - but it's not going to save money in year 1 or year 2, it'll save money in year 10,11,15 and 20. If we're doing a good job on prevention and are reducing rates of obesity - if we went back to the obesity rates that existed back in 1980, we'd save the system a trillion dollars, but we're not going to do that over night - it's going to take some time."

Even before undertaking reform of the broader elements of the healthcare system, the President signed to law the American Recovery and Reinvestment Act, better known as the stimulus bill - an injection of US $\$ 787$ billion into the American economy. Several provisions within the stimulus bill will impact personalized medicine, including:

- NIH research funding: most personalized diagnostics and therapeutics have their genesis in basic research. The stimulus bill has an additional US $\$ 8.7$ billion for the NIH to fund disease research in areas such as Alzheimer's, Parkinson's, cancer and heart disease.

- Prevention and wellness: there is US $\$ 1$ billion of funding available for prevention and wellness programs. Of that total, US $\$ 300$ million is targeted for immunization programs and US $\$ 50$ million goes to the states for combating healthcare-related infections. Even so, the remaining US\$650 million is a historic commitment to prevention efforts.

- Comparative effectiveness review (CER): the stimulus bill contains US $\$ 1.1$ billion to conduct or support research to evaluate and compare the outcomes, effectiveness, risk and 
benefits of medical treatments and services. While comparative effectiveness may sound like a lackluster name for a dry study of health economics, it may well ignite one of the most important policy debates surrounding personalized medicine. CER will be discussed in greater detail later in this article, but in the context of the stimulus bill, CER is noteworthy since the Obama administration and Congress have taken the concept from the theoretical and translated it to the real.

- Health IT: the stimulus bill provides US $\$ 19$ billion to oversee the development and implementation of a nationwide health IT infrastructure. Interestingly, much of the stimulus bill provides funding for the various agencies, with little direction regarding how the money should be spent. In contrast, the Health IT section of the bill sets out, in precise detail, the specific programs and, in some cases, how they are to be administered. Since the stimulus bill was, for better or worse, drafted in the US House of Representatives and the Senate, not in the White House, this demonstrates the interest that not only the President has, but also the congressional leadership has in the nation's health information architecture.

The stimulus bill has not been President Obama's only act to support personalized medicine in his new administration. Early on, the President nominated Dr Eric Lander of the Massachusetts Institute of Technology (MIT) Broad Institute (MA, USA) and Dr Harold Varmus, a Nobel Laureate, former director of the NIH and the President of Memorial SloanKettering Cancer Center (NY, USA) to co-chair the PCAST. Dr Lander and Dr Varmus are two of the country's most prominent scientists. Their joint chairmanship of the PCAST makes it more likely that the interest in personalized medicine, kindled under the Bush administration, will continue throughout the Obama era.

Meanwhile, on 9 March 2009, the President kept a commitment he made in the campaign, and signed an executive order to lift the ban on the federal funding of stem-cell research imposed by President Bush in 2001.

\section{What lies ahead}

On 26 February 2009, the Obama administration unveiled its budget for 2010. In a speech to Congress two nights previously, the President made it clear that, despite the struggling economy, he was not prepared to wait for better days to undertake the priority issues of his administration, including most notably, healthcare reform. To that end, the President's budget contains plans to set aside US $\$ 634$ billion over 10 years to pay for an effort that, as the President said, has eluded every President since Teddy Roosevelt.

To critics who claim Obama's administration is taking on too many expensive issues too soon, the President's reply is that with healthcare accounting for $16 \%$ of the US gross domestic product and rising, healthcare reform is part and parcel of long-term economic recovery.

Regardless of how one feels about that argument, the President has done something politically interesting with the budget. He has, in essence, set aside the money to pay for healthcare reform but deferred to Congress to bring him the blueprint on how to do so. This breaks the orthodoxy of how the executive and legislative branches normally interact, but in this case, it may make sense. From a practical perspective, the new administration has only in recent days begun to fill out the ranks of its senior healthcare policy positions, including a new nominee to head HHS, Governor Kathleen Sebelius of Kansas, USA. Yet the major congressional committees that will oversee healthcare reform have been working in earnest since last summer, holding public hearings and meeting extensively in private. The committee chairmen, including Senator Edward Kennedy who chairs the Senate Committee on Health, Education, Labor and Pensions (DC, USA), believe comprehensive legislation could be on the table as early as June 2009 .

\section{"To critics who claim Obama's admin- istration is taking on too many expensive issues too soon, the President's reply is that ... healthcare reform is part and parcel of long-term economic recovery."}

Aside from overall healthcare reform, Senator Burr has expressed interest in introducing a new version of the personalized medicine legislation. The search is underway to find a Democrat to serve as a cosponsor for the bill, while Representative Kennedy has also expressed support for a new version in the US House of Representatives. Indeed, the White House may even be able to implement some of the ideas in these bills via executive order from the President.

In addition, Senator Kennedy is likely to introduce legislation to govern the regulatory oversight of laboratory-developed tests. Thus, the debate played out last year over the IVD/MIA guidelines 
and the Genentech petition could find itself being waged this year in the halls of Congress, as well as at the FDA. There may also be legislation to expand the coverage of GINA.

In addition, Congress is by no means finished with the issue of CER, and it is around this issue that personalized medicine may confront some of its toughest challenges. Put more simply, there is a debate over whether CER is a tool to combat rising healthcare costs or a tool to bring greater value to healthcare. Before the stimulus bill was crafted, the Senate and the House had already embarked on markedly different journeys in the quest to define what is 'comparatively effective', and this was reflected in the report language that accompanied the final compromised stimulus bill. Unfortunately, the CER provisions of the stimulus bill are written in such a way as to result in one-size-fits-all comparative clinical trials that do not incorporate the targeting of therapies to improve their relative effectiveness based on appropriate segmentation of patients.

\section{"The challenge of this generation is to transform healthcare from medicine as we have known it, to medicine as we believe it can be."}

Aside from Congress, various federal agencies will continue a host of other activities related to personalized medicine. For example, the FDA recently announced the creation of a new position within the office of the Agency's Chief Scientist, to coordinate genomics-related activities. CMS has embarked on hearings to determine whether it will cover molecular diagnostics and screening tests under Medicare and Medicaid reimbursement. Several agencies have been coordinating efforts to write the regulations implementing GINA, and these should be published later this year. Finally, the National Institute for Standards and Technology (NIST [MD, USA]), through its Technology Innovation Program, is soliciting a series of white papers covering a wide range of areas, including personalized medicine, which might lead to additional research funding.

Even the third branch of the government, the judiciary, may be involved in determining public policy in personalized medicine, should a court case present the opportunity to rule on the longsimmering area of the legality of gene patents or other controversial areas of intellectual property, as they relate to biotechnology.

\section{Conclusion}

The challenge of this generation is to transform healthcare from medicine as we have known it, to medicine as we believe it can be. Ideally, the modifier 'personalized' will fall away as all medicine will be 'personal', be it diagnosis of disease, a treatment decision or a prevention strategy.

The hurdles to that future are well known and formidable. These include, finding investment for young companies, convincing payers to believe in the value of proposition, building a regulatory structure that promotes safety and efficacy but does not stifle innovation, shifting the economic calculations to reward value-based products and services... The list is endless and it can be frustrating at times to stop and realize how much remains to be done.

And yet it can also be encouraging to step back and to look at how far the discussion has come, how much progress is being made, not in single sweeping actions but by a score of smaller actions. Even the President of the USA sees personalized medicine as part of meeting the nation's healthcare challenge.

The path to personalized medicine will clearly involve many sectors, with scientific discovery and the practice of medicine being justly in the lead. But public policy will play a crucial role, perhaps the defining one, as a referee between the various competing interests. A total of 100 days into a new presidency, surveying that policy agenda, though it is complex and often contentious, offers cautious cause for optimism.

\section{Financial \& competing interests disclosure}

The author has no relevant affiliations or financial involvement with any organization or entity with a financial interest in or financial conflict with the subject matter or materials discussed in the manuscript. This includes employment, consultancies, honoraria, stock ownership or options, expert testimony, grants or patents received or pending, or royalties.

No writing assistance was utilized in the production of this manuscript. 